\title{
BM] Global Health Proactive case detection of common childhood illnesses by community health workers: a systematic review
}

Caroline Whidden (D) , ${ }^{1}$ Julie Thwing, ${ }^{2}$ Julie Gutman, ${ }^{2}$ Ethan Wohl, ${ }^{3}$ Clémence Leyrat, ${ }^{4}$ Kassoum Kayentao, ${ }^{5}$ Ari David Johnson, ${ }^{6}$ Brian Greenwood, ${ }^{1}$ Daniel Chandramohan ${ }^{1}$

To cite: Whidden C, Thwing J, Gutman J, et al. Proactive case detection of common childhood illnesses by community health workers: a systematic review. BMJ Global Health 2019;4:e001799. doi:10.1136/ bmjgh-2019-001799

Handling editor Seye Abimbola

Received 28 June 2019 Revised 25 September 2019 Accepted 28 September 2019

Check for updates

C Author(s) (or their employer(s)) 2019. Re-use permitted under CC BY-NC. No commercial re-use. See rights and permissions. Published by BMJ.

For numbered affiliations see end of article.

Correspondence to

Caroline Whidden;

Caroline.Whidden@|shtm.ac.uk

\section{ABSTRACT}

Introduction Identifying design features and implementation strategies to optimise community health worker (CHW) programmes is important in the context of mixed results at scale. We systematically reviewed evidence of the effects of proactive case detection by CHWs in low-income and middleincome countries (LMICS) on mortality, morbidity and access to care for common childhood illnesses.

Methods Published studies were identified via electronic databases from 1978 to 2017. We included randomised and non-randomised controlled trials, controlled before-after studies and interrupted time series studies, and assessed their quality for risk of bias. We reported measures of effect as study investigators reported them, and synthesised by outcomes of mortality, disease prevalence, hospitalisation and access to treatment. We calculated risk ratios (RRs) as a principal summary measure, with Cls adjusted for cluster design effect. Results We identified 14 studies of 11 interventions from nine LMICs that met inclusion criteria. They showed considerable diversity in intervention design and implementation, comparison, outcomes and study quality, which precluded meta-analysis. Proactive case detection may reduce infant mortality (RR: 0.52-0.94) and increase access to effective treatment (RR: 1.59-4.64) compared with conventional community-based healthcare delivery (low certainty evidence). It is uncertain whether proactive case detection reduces mortality among children under 5 years (RR: 0.04-0.80), prevalence of infectious diseases (RR: 0.06 1.02), hospitalisation (RR: $0.38-1.26$ ) or increases access to prompt treatment (RR: 1.00-2.39) because the certainty of this evidence is very low.

Conclusion Proactive case detection may provide promising benefits for child health, but evidence is insufficient to draw conclusions. More research is needed on proactive case detection with rigorous study designs that use standardised outcomes and measurement methods, and report more detail on complex intervention design and implementation. PROSPERO registration number CRD42017074621.

\section{INTRODUCTION}

Community health worker (CHW) programmes are experiencing a resurgence as a strategy to achieve health-related sustainable development goals. Many low-income and middle-income countries (LMICs) have

\section{Key questions}

What is already known?

- While many low-income and middle-income countries (LMICs) are adopting community health worker (CHW) programmes as an evidence-based strategy to achieve global health goals, the expected benefits have not been realised in all contexts.

- Recent reviews for developing global guidelines to optimise CHW programmes found a scarcity of evidence on best practices for CHW education, deployment and management.

What are the new findings?

- Proactive case detection of common childhood illnesses by CHWs in LMICs may reduce infant mortality and increase access to effective treatment compared with conventional community-based healthcare delivery (low certainty evidence).

- Studies assessing the effects of proactive case detection showed considerable diversity in terms of participants, interventions, comparisons, outcomes and study quality.

What do the new findings imply?

- Proactive case detection may be more effective than conventional community-based healthcare delivery in achieving child health gains.

- More implementation research is needed with rigorous study designs and standardisation of outcomes to optimise the design and implementation of CHW programmes for impact.

implemented integrated Community Case Management (iCCM) of common childhood illnesses, ${ }^{12}$ a package of services delivered by CHWs to diagnose, treat and refer children under 5 with malaria, diarrhoea, pneumonia and malnutrition in the community setting. ${ }^{3}$ This strategy has shown an increase in access to care and reduced child mortality. ${ }^{4-12}$ However, the expected benefits have not been realised in all contexts. ${ }^{13-18}$ Several recent evaluations of national iCCM programmes in 
Burkina Faso, Ethiopia and Malawi did not find impacts on care-seeking or child mortality. ${ }^{19-22}$

These programmes shared certain design features that may have contributed to the lack of overall effects by not addressing barriers to care, such as user fees for services, ${ }^{23-25}$ lack of adequate CHW supervision, ${ }^{26-28}$ or provision only for patients who sought care from a fixed site. As more countries scale up CHW programmes, it is critical to understand how to best design and implement iCCM, and CHW services more broadly, in order to realise their full potential.

A recent series of systematic reviews to inform WHO guidelines for optimising CHW programmes found a scarcity of evidence on best practices for several key policy areas, including CHW training, supervision and deployment, and calls specifically for more research on CHW workflow. ${ }^{29}$ We conducted a systematic review of the evidence for the effectiveness of proactive case detection by CHWs to improve access to care and reduce morbidity and mortality. By proactively seeking out patients at home to offer diagnosis and treatment or referral, a proactive workflow has the potential to overcome barriers to care, including direct and indirect costs, distance, mistrust and gender inequality, reduce the time from onset of a condition to services, and consequently reduce disease progression and mortality.

\section{METHODS \\ Inclusion criteria}

Study designs

Studies from LMICs involving community-based, proactive case detection of common childhood illnesses were identified. Anticipating that randomised trials of healthcare service delivery would be very few, we included a broader range of study designs in line with Cochrane Effective Practice and Organisation of Care (EPOC) group recommendations. ${ }^{30}$ These included randomised controlled trials (RCTs) and non-randomised controlled trials (NRCTs), controlled before-after (CBA) studies, interrupted time series (ITS) and repeated measure studies.

\section{Interventions and comparisons}

To be eligible for inclusion, studies needed to evaluate a primary healthcare intervention that included proactive case-finding home visits by CHWs for the purpose of searching for and identifying, through history and/or diagnostics, cases of common childhood illness, including malaria, diarrhoea, pneumonia, malnutrition, HIV or tuberculosis. These conditions were chosen because they are covered by international protocols for iCCM of common childhood illnesses ${ }^{31}$ and/or contribute a substantial disease burden in LMICs. Studies needed to compare proactive healthcare delivery to usual or supplemented primary care available from facilities and/or CHWs that did not involve home visits for the purpose of identifying sick patients.

\section{CHWs and trial participants}

In accordance with earlier reviews, a CHW was defined as any lay health worker who received training to perform tasks related to primary healthcare delivery but had not received professional medical or paramedical education. $^{32}$ Recipients of proactive case-finding home visits had to include children under 5 years of age.

\section{Outcomes}

We included studies if they assessed any of the following outcomes: (1) mortality among children under 5 years of age or infants aged $0-11$ months; (2) prevalence or incidence of disease; (3) hospitalisation; (4) access to healthcare services; (5) harms or adverse effects; (6) costs or economic effects.

Our review focused on assessing proactive case detection as an adjoint to iCCM. As causes of neonatal deaths in LMICs differ from those of post-neonatal child deaths, we did not include studies that were restricted to neonates, that is, intervening solely in the neonatal period and reporting solely on neonatal outcomes. Nevertheless, we retained studies from our search that assessed childhood illness starting from the first day of life and reported outcomes separately for neonates and infants.

\section{Search strategy}

We searched the following electronic databases for studies meeting the eligibility criteria, in addition to contacting researchers with expertise relevant to the review topic:

- MEDLINE Ovid (1946 to September Week 4 2017) (searched 10 October 2017);

- Embase (1947 to 2017 October 20) (searched 23 October 2017);

- Global Health Database (1910 to 2017Week 41) (searched 23 October 2017);

- Cochrane Central Register of Controlled Trials (searched 9 November 2017);

- WHO Library (searched 30 November 2017).

The search strategy included terms to capture the following concepts describing the intervention: (i) proactive case detection-broad search terms were used to maximise sensitivity given a lack of MeSH terms for this concept; (ii) CHWs-search terms were adapted from a review by Lewin and colleagues ${ }^{32}$ and (iii) condition. A combination of two methodological search filters was adapted to capture a fourth concept for appropriate study design: (iv) the sensitivity-maximising Cochrane MEDLINE filter for RCTs and an EPOC filter for nonrandomised trials. The search included publications since 1978, the year of the Alma-Ata Declaration, which marked a restructuring of the global health agenda towards primary healthcare provision by CHWs. No language restrictions were applied. Full strategies and results are provided in online supplementary file 1 .

\section{Data collection and analysis}

Selection of studies

Studies retrieved from the search were uploaded onto Covidence, a Cochrane technology platform for systematic reviews. ${ }^{33}$ Two reviewers (CW and JT or JG) independently screened titles, abstracts and full-text articles 
for eligibility. Inclusion was determined by consensus or in consultation with a third reviewer (JT or JG).

\section{Data extraction and quality assessment}

Two reviewers (CW and EW) independently extracted data from included studies related to study identification, methods, population, interventions, implementation of intervention, outcomes and results using a data extraction form designed in Covidence. Two reviewers (CW and $\mathrm{EW}$ ) independently assessed the quality of included studies using the EPOC risk of bias tool for studies with a separate control group; ${ }^{34}$ allocation concealment was removed from the quality assessment criteria as reviewers deemed this domain inapplicable due to the nature of the intervention under review. Consensus on data extraction and quality assessment was reached in discussion or in consultation with a third reviewer (JT or JG).

\section{Data synthesis}

We reported measures of effect in the same way that study investigators reported them and synthesised them by type of outcome. For studies with a separate control group, we included only the measure of effect derived by comparing the intervention group to the control group, if multiple comparisons were reported. For studies with no separate control group, we included baseline to end-line comparisons. We calculated risk ratios (RRs) for dichotomous data to allow for comparisons across studies. If appropriate denominators (eg, number of live births for mortality outcomes) were not reported, we used population estimates reported in the study to approximate the denominator. We calculated 95\% CIs, adjusting for clustering using the intracluster correlation coefficient (ICC) reported in the study, if available. ${ }^{35}$ If not available, we used a conservative ICC of 0.05 for all studies with a cluster design, as the ICC was $<0.001$ in the three studies for which it was reported. We assessed heterogeneity across studies for each outcome type both qualitatively and quantitatively using the $\mathrm{I}^{2}$ statistic, which describes the percentage of total variation across studies that is due to heterogeneity rather than chance. ${ }^{36}$ Two reviewers (CW and JT or JG) independently assessed the certainty of evidence for each analysis using the Grading of Recommendations, Assessment, Development and Evaluation approach, ${ }^{37} 38$ which takes into account study design, risk of bias, inconsistency, indirectness/applicability, imprecision and strength of association. Consensus was reached through discussion or in consultation with a third reviewer (JT or JG).

\section{RESULTS}

\section{Characteristics of included studies}

Excluding duplicates, a total of 442 abstracts were screened for eligibility (figure 1 in online supplementary file 2). Fourteen studies were included, including five cluster RCTs (table 1). Complete information on the characteristics and risk of bias for each study is available in online supplementary file 3 .
Study settings

Among the 14 included studies, seven were from Africa (three KwaZulu-Natal, South Africa, ${ }^{39-41}$ two Mali, ${ }^{42} 43$ one Ethiopia ${ }^{44}$ and one Senegal. ${ }^{45}$ The two reports from $\mathrm{Mali}^{4243}$ and the two from rural South Africa, ${ }^{40}{ }^{41}$ respectively, studied the same interventions delivered to the same populations, differing only with regard to whenand in South Africa, how-impact was assessed. Six studies were from Southeast Asia (three India, ${ }^{46-48}$ one Bangladesh, ${ }^{49}$ one $\mathrm{Nepal}^{50}$ and one Pakistan. ${ }^{51}$ Two reports from Haryana, India ${ }^{478}$ evaluated the same intervention delivered to the same population but assessed different outcomes. One study was from the Americas, in Dominican Republic. ${ }^{52}$ Four studies took place in urban or periurban settings, ${ }^{39} 424352$ and eight in rural settings; ${ }^{40} 4144-4649-51$ the studies in Haryana ${ }^{47} 48$ did not indicate whether the setting was rural or urban.

\section{Study designs and outcomes}

The KwaZulu-Natal, South Africa ${ }^{39-41}$ and Haryana, India ${ }^{478}$ studies were cluster RCTs that evaluated a range of access to care, morbidity and mortality outcomes; the rural South Africa study did not report outcomes separately for children under 5 years. ${ }^{40}{ }^{41}$ Two studies were NRCTs that measured morbidity outcomes; ${ }^{49} 52$ the Bangladesh study did not report outcomes separately for children under 5 years. ${ }^{49}$ The Nepal study ${ }^{50}$ that used a non-randomised, stepped-wedge design to assess risk of death among infants and children did not compare results between early and late treatment groups. Instead, it compared annual risks to baseline and used a test for trend to assess programme maturity. This study was therefore considered in this review to be an uncontrolled before-after study from baseline to end-line.

Four studies used a CBA design ${ }^{44-46} 51$ and reported percent differences or difference-in-differences for mortality, morbidity or access to care outcomes. However, some did not use the baseline or control group appropriately. The Pakistan study ${ }^{51}$ reported different baseline years for intervention and control areas; therefore, this study was deemed a NRCT and only the postintervention comparison between groups was presented in this review. The Ethiopia study ${ }^{44}$ presented a number of before-after access to care indicators for the intervention group, but only present before-after data for the comparison group for one outcome, the tuberculosis case notification rate; outcomes were not reported separately for children under 5 years. Finally, the Mali studies ${ }^{42}{ }^{43}$ were included as ITS designs; yet, with only one baseline, they lacked a comparative preintervention trend and thus were treated in the review as uncontrolled before-after studies from baseline to end-line.

\section{Participants}

Half of the studies extended CHW services to the entire population, ${ }^{42-45} 495354$ among which only the Mali 


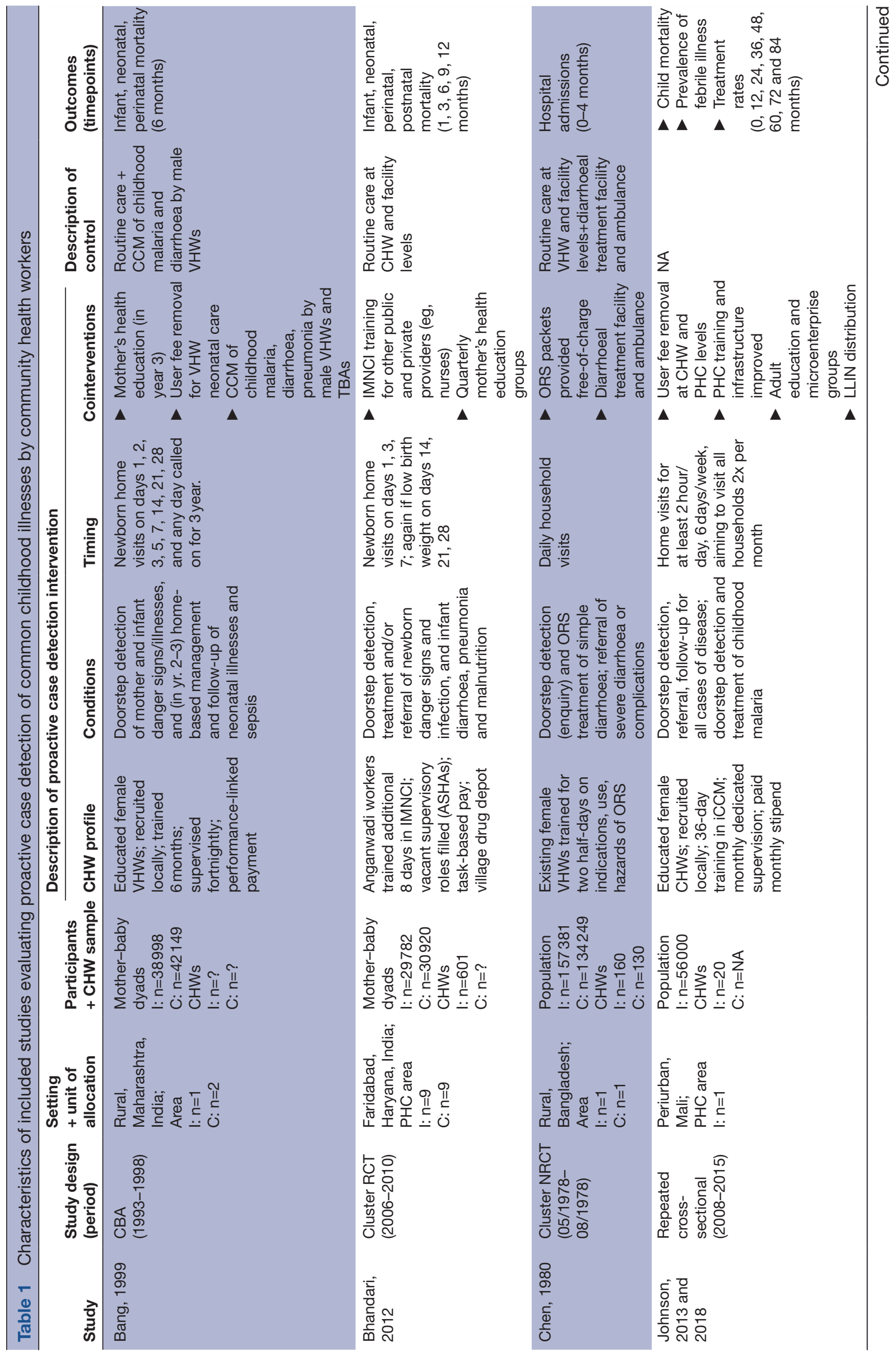




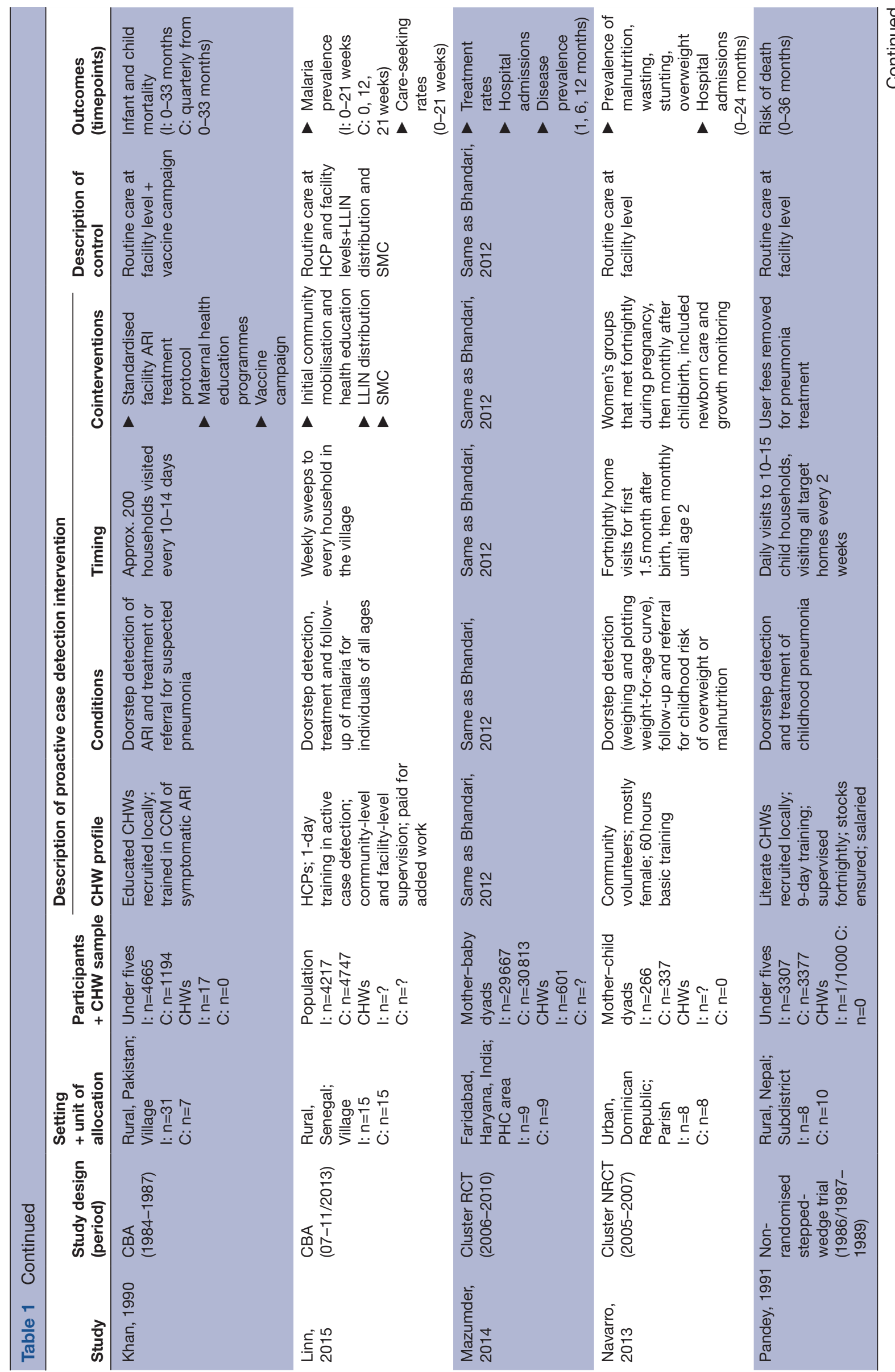




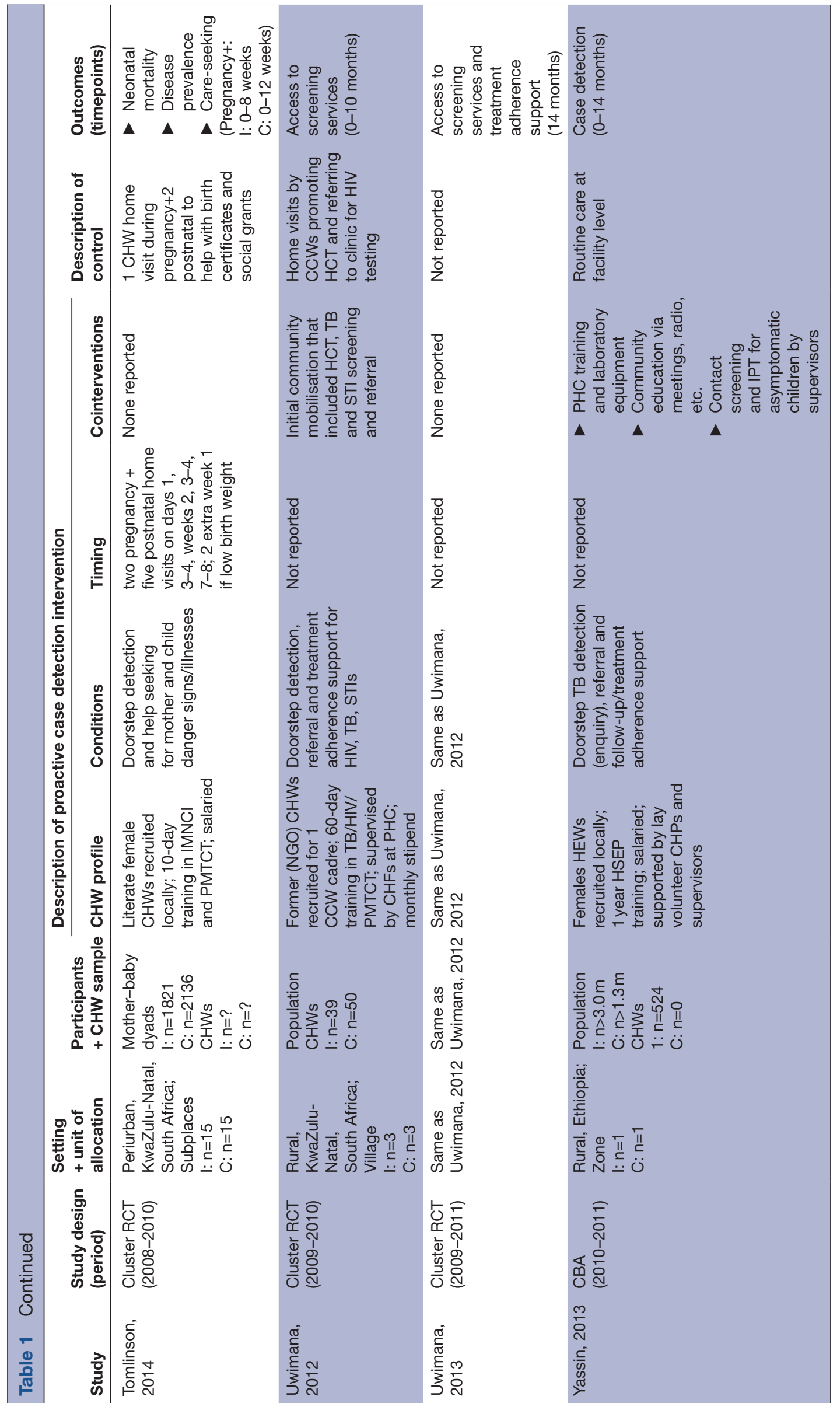

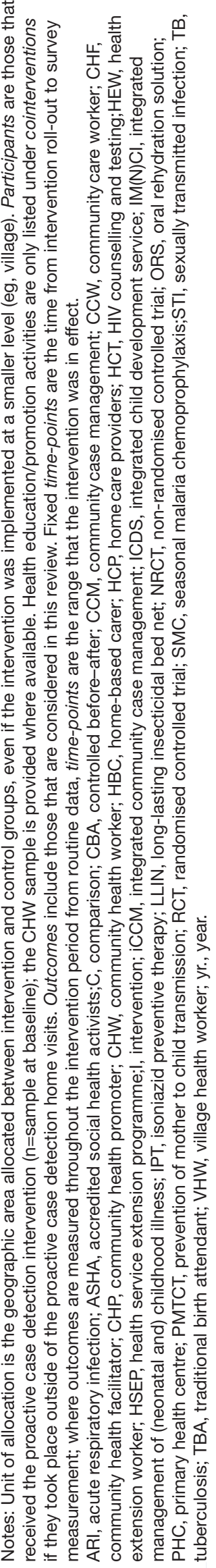


studies ${ }^{42}{ }^{43}$ reported outcomes specifically for children under 5 years. Five studies recruited pregnant women and delivered a mother-child intervention during the neonatal period, and in some cases, into infancy and childhood. ${ }^{39} 46-4852$ The remaining two studies tested interventions that targeted children under 5 years of age during a period of 3 years. ${ }^{50} 51$

\section{Characteristics of CHW programmes}

The Bangladesh, ${ }^{49}$ Ethiopia, ${ }^{44}$ Senegal, ${ }^{45}$ rural South Africa $^{4041}$ and more recent India ${ }^{47}$ studies provided supplemental training in the context of the study (twohalf days in Bangladesh, 1 day in Senegal, 8 days in India, 60 days in South Africa and unreported in Ethiopia) to CHWs from an already established CHW cadre. The remaining studies evaluated CHW programmes initiated by a research institute, all of which recruited local, literate community members and trained them for a duration of 60 hours $^{52}$ to 6 months. ${ }^{46}$ In half of all programmes, CHWs were exclusively or predominantly female. Reporting of recipient and CHW sample sizes, and therefore CHW to population ratios, was poor.

Eleven studies reported enhanced CHW supervision as an adjunct to the intervention. However, the supervision strategy and frequency were not adequately described. Supervisors included physicians, ${ }^{46}$ nurses,${ }^{51}$ accredited social health activists ${ }^{47} 48$ or senior project staff ${ }^{42} 50$ who monitored CHW activities periodically. Other studies employed a dedicated cadre of CHW supervisors, either based at the facility ${ }^{40}$ or in the community. ${ }^{43}{ }^{44}$ Eleven studies paid CHWs for their work, with a salary in-line with government standards, ${ }^{39} 434450$ a performancelinked ${ }^{46}$ or task-based ${ }^{478}$ remuneration scheme, or some other form of payment. ${ }^{404145}$

CHWs provided services for the range of conditions eligible for inclusion in the review. CHWs in Mali, ${ }^{42}{ }^{43}$ India ${ }^{46-48}$ and periurban South Africa ${ }^{39}$ provided integrated management of common neonatal and childhood illnesses. CHWs provided care exclusively for diarrhoea in Bangladesh; $;{ }^{49}$ for pneumonia in Pakistan and Nepal; $; 051$ for malaria in Senegal; ${ }^{45}$ for malnutrition and at risk of being overweight in Dominican Republic $;^{52}$ for tuberculosis in Ethiopia; ${ }^{44}$ and for HIV, tuberculosis, and sexually transmitted infections in rural South Africa. ${ }^{40}$ In addition to proactive case detection, most studies included doorstep treatment by CHWs and referral to a facility if necessary, with the exception of the studies in Dominican Republic, Ethiopia and periurban South Africa, ${ }^{39} 4452$ which limited postdetection activities to referral for treatment and home-based follow-up.

Most studies compared proactive case detection by CHWs to the standard of care-passive case detection at public or private health facilities; six studies also included passive case detection by CHWs in the control arm. The South African studies included control CHWs who conducted home visits for purposes other than proactive case detection. Control arm CHWs conducted one pregnancy and two postnatal home visits to assist with securing identity documents and social grants in the urban study, ${ }^{39}$ and home visits to promote and refer clients to HIV counselling and testing in the rural studies. ${ }^{40}$

\section{Risk of bias of included studies}

Risk of bias summaries are provided in online supplementary file 2 (figure 2 and figure 3). Risk of bias assessments for each study are provided in online supplementary file 3 . These assessments were considered when interpreting the results and certainty of evidence for each outcome.

\section{Selection bias}

All studies, with the exception of those in Mali, ${ }^{42} 43$ allocated the study area into intervention and control groups. Five studies used cluster randomisation to assign groups. ${ }^{39-41} 4748$ Among seven studies that did not use random allocation, sufficient evidence was provided in only two ${ }^{45} 46$ that outcome measurements were similar between groups at baseline, and in only three ${ }^{465052}$ that population-level and/or cluster-level characteristics were similar between groups at baseline.

\section{Performance bias and detection bias}

Due to the nature of the intervention, blinding of participants and study personnel to allocation assignment was not possible and was scored high risk for all included studies. All six Southeast Asian studies ${ }^{46-51}$ and the periurban South Africa study ${ }^{39}$ blinded outcome assessors to allocation assignment, earning a low detection bias score.

\section{Attrition bias}

Reporting of incomplete outcome data varied considerably between studies. Studies involving pregnant women for a neonatal intervention discussed attrition bias with the use of a trial profile. ${ }^{39474852}$ A Data Safety and Monitoring Board stopped the Haryana, India trials early after the required sample size had been met, but prior to about half of children completing the 12-month assessment. ${ }^{47} 48$ Risk of attrition bias was high in the Dominican Republic study where roughly a quarter of mother-child dyads were lost, and there were statistically significant differences in some baseline characteristics that could be associated with the outcome between those who completed follow-up and those who did not. ${ }^{52}$ Missing survey data for date of birth and death were imputed in the Mali studies, but the extent and patterns of missing data were explicitly reported. ${ }^{42}{ }^{43}$ Studies from India ${ }^{46}$ and Nepal ${ }^{50}$ did not comment on completeness of outcome data, but data were collected by an independent set of workers and analysed on an intention to treat basis. CBA studies in Pakistan ${ }^{51}$ and Senegal ${ }^{45}$ relied on CHWs to collect outcome data in intervention clusters and employed periodic surveys in control clusters. These studies did not discuss incomplete outcome data and were scored high risk due to the differences in data source and methods between the two groups. 


\section{Reporting bias}

A published protocol was found for only one study. ${ }^{39}$ No studies reported outcomes in the methods that were then subsequently omitted from the results and, therefore, no studies were scored as being at high risk of reporting bias. Some studies subsequently added outcomes from posthoc analyses, but provided justifiable reasons for inclusion of the additional outcomes that were not prespecified. ${ }^{39} 4748$

\section{Protection against contamination}

Risk of bias due to contamination was scored as low when large units of allocation were chosen and efforts to minimise contamination were discussed and/or a map was provided showing geographic separation of groups. ${ }^{446-50}$

\section{Effects of interventions}

Eleven studies assessed the effects of proactive case detection of common childhood conditions by CHWs on mortality, morbidity or access to curative services and were included in the main analysis. Meta-analysis was deemed inappropriate as the studies in each analysis represented considerable clinical diversity with respect to intervention and participant characteristics, methodological diversity with respect to study design and risk of bias, and statistical heterogeneity as quantified by the $\mathrm{I}^{2}$ statistic. We were unable to explore this heterogeneity by prespecified subgroup analyses due to the limited number of studies. Overall, the certainty of evidence is low or very low because of limitations in study design, indirect measures of effect due to cointerventions or comparisons and unexplained heterogeneity.

\section{Mortality}

Seven studies measured mortality outcomes (table 2; Figure 1). Proactive case detection may reduce neonatal mortality (low certainty evidence). However, the effects vary and it is possible that it makes little or no difference to neonatal mortality (calculated RRs: 0.43 to 1.07 ; $\mathrm{I}^{2}=79.1 \%$ ). Proactive case detection may reduce infant mortality (calculated RRs: 0.52 to $0.94 ; \mathrm{I}^{2}=61.9 \%$ ) (low certainty evidence). It is uncertain whether proactive case detection reduces mortality among children under 5 years (calculated RRs: 0.04 to $0.80 ; \mathrm{I}^{2}=94.4 \%$ ) because the certainty of this evidence is very low.

Three studies assessed impact on neonatal mortality over a 2-3year timeframe (table 2; Figure 1). It was the primary outcome in the Maharashtra ${ }^{46}$ and Haryana ${ }^{47}$ studies of proactive case detection of newborn and infant danger signs, infections and illnesses. In rural Maharashtra, there was a $62 \%$ reduction in intervention areas compared with control areas $(p<0.001) .{ }^{46}$ In Haryana, the neonatal mortality rate beyond the first 24 hours of life was lower in intervention clusters than in control clusters (adjusted HR $=0.86$; 95\% CIs: 0.79 to 0.95 ), but not the case for the neonatal mortality rate overall-an effect, they explained, due to the higher than expected proportion of neonatal deaths occurring in the first 24 hours on which the intervention was unlikely to have had an effect. ${ }^{47}$ In both Maharashtra and Haryana, intervention groups included a mother's education component and system strengthening in terms of user fee removal for CHW care $^{46}$ or training of other provider cadres in Integrated Management of Newborn and Childhood Illnesses. ${ }^{47}$ An exploratory analysis of the effect of a home visit programme in periurban South Africa to improve appropriate infant feeding and HIV-free infant survival ${ }^{39}$ on neonatal mortality showed an increased risk of death in intervention compared with control clusters, although the effect was not statistically significant ( $R R=1.07 ; 95 \%$ CIs: 0.69 to 1.63 ).

Four Southeast Asia studies assessed infant mortality. The Maharashtra ${ }^{46}$ and Haryana ${ }^{47}$ studies found significant reductions (respectively, 45.7\%; $\mathrm{p}<0.001$ and $\mathrm{AHR}=0.89 ; 95 \%$ CIs: 0.78 to 1.00 ) in infant mortality between intervention and controls. Proactive case detection of childhood respiratory infection and doorstep treatment of suspected pneumonia compared with facilitybased care led to reductions in infant mortality in rural Nepal,${ }^{50}$ where cotrimoxazole was provided at home free of charge, and in rural Pakistan, ${ }^{51}$ where CHWs treated at home or referred to facilities where treatment protocols had been standardised. In Nepal, the greatest reduction in mortality after 3 years of intervention activities was seen in infants aged $6-11$ months $(\mathrm{RR}=0.36 ; 95 \%$ CIs: 0.24 to 0.56 ). In Pakistan, ${ }^{51}$ the infant mortality rate was $74 / 1000$ in the intervention area during the first 2 years of the study compared with 93/1000 in the control area.

A reduction in mortality was seen for all children under 5 years of age in Nepal, with a relative risk reduction of 0.72 from baseline to year $3,{ }^{50}$ and in Pakistan, with a $26 \%$ reduction between intervention (29/1000) and control $(39 / 1000)$ areas during the first 2 years of the study. ${ }^{51}$ In periurban Mali, the under-5 mortality rate declined from $154 / 1000$ at baseline to $25 / 1000$ after 3 years of proactive case detection of common childhood conditions in addition to primary health centre reinforcements and removal of user fees, and to $7 / 1000$ after 7 years. ${ }^{43}$

\section{Morbidity}

Six studies assessed prevalence of disease, and four assessed hospitalisation (table 3; Figure 2). Proactive case detection may improve nutritional outcomes (low certainty evidence), although the effects vary, and it is possible that it makes little or no difference to nutritional outcomes (calculated RRs range from 0.61 to $1.16 ; \mathrm{I}^{2}=61.4 \%$ ). It is uncertain whether proactive case detection reduces the prevalence of infectious diseases (calculated RRs: 0.06 to $1.02 ; \mathrm{I}^{2}=90.6 \%$ ) or hospitalisation (calculated RRs: 0.38 to $1.26 ; \mathrm{I}^{2}=94.5 \%$ ) because the certainty of this evidence is very low.

In Mali ${ }^{42}{ }^{43}$ and rural Senegal, ${ }^{45}$ proactive case detection of malaria led to significant reductions in the odds of febrile illness among children under five (adjusted OR (AOR) after 7 years $=0.45$; $95 \%$ CIs: 0.32 to 0.62 ), and symptomatic malaria among the general population in intervention villages compared with control 
Table 2 Intervention effects on mortality outcomes

\begin{tabular}{|c|c|c|c|c|}
\hline Country & Design* & $\begin{array}{l}\text { Reported measure of effect }(95 \% \\
\text { Cls)† }\end{array}$ & Calculation of risk $\ddagger$ & Calculated RR§ \\
\hline \multicolumn{5}{|c|}{ Neonatal mortality } \\
\hline India ${ }^{46}$ q & CBA & $\%$ diff=62.2\%; $p<0.001$ & $\begin{array}{l}\text { I: } 25 / 979 \\
\text { C: } 66 / 1108\end{array}$ & $0.43(0.27,0.67)$ \\
\hline India ${ }^{47}$ I & cRCT & $\mathrm{AHR}=0.91(0.80$ to 1.03$)$ & $\begin{array}{l}\text { I: } 1244 / 29667 \\
\text { C: } 1326 / 30813\end{array}$ & $0.97(0.71,1.33)$ \\
\hline $\mathrm{SA}^{39}$ & $\mathrm{cRCT}$ & $\mathrm{RR}=1.07$ (0.69 to 1.63$)$ & $\begin{array}{l}\text { I: } 20 / 1821 \\
\text { C: } 22 / 2136\end{array}$ & $1.07(0.58,1.95)$ \\
\hline \multicolumn{5}{|c|}{ Infant mortality } \\
\hline India ${ }^{46}$ & CBA & $\%$ diff=45.7\%; $p<0.001$ & $\begin{array}{l}\text { I: } 38 / 979 \\
\text { C: } 83 / 1108\end{array}$ & $0.52(0.36,0.75)$ \\
\hline India ${ }^{47}$ | & cRCT & $\mathrm{AHR}=0.89(0.78$ to 1.00$)$ & $\begin{array}{l}\text { I: } 1925 / 29667 \\
\text { C: } 2136 / 30813\end{array}$ & $0.94(0.73,1.20)$ \\
\hline Nepal $^{50}$ & $\mathrm{BA}$ & $\begin{array}{l}0 \text { to } 6 \text { days: } R R=0.80(0.59,1.10) \\
0.25 \text { to } 5 \text { months: } R R=0.74(0.58,0.94) \\
6 \text { to } 11 \text { months: } R R=0.36(0.24,0.56)\end{array}$ & $\begin{array}{l}\text { I: } 236 / 13406 \\
\text { C: } 199 / 6684\end{array}$ & $0.60(0.37,0.96)$ \\
\hline Pakistan ${ }^{51} \emptyset$ & cNRCT & $\%$ diff=21\%; 'not significant' & $\begin{array}{l}\text { I: } 108 / 4665 \\
\text { C: } 31 / 1194\end{array}$ & $0.87(0.52,1.46)$ \\
\hline \multicolumn{5}{|c|}{ Child mortality } \\
\hline $\mathrm{Mali}^{42}$ & $\mathrm{BA}$ & $H R=0.10 ; p<0.0001$ & $\begin{array}{l}\text { I: } 29 / 1390 \\
\text { C: } 38 / 316\end{array}$ & $0.17(0.11,0.28)$ \\
\hline $\mathrm{Mali}^{43}$ & $\mathrm{BA}$ & $\mathrm{HR}=0.039(0.013$ to 0.116$)$ & $\begin{array}{l}\text { I: } 5 / 1023 \\
\text { C: } 39 / 330\end{array}$ & $0.04(0.02,0.10)$ \\
\hline $\mathrm{Nepal}^{50} q$ & $\mathrm{BA}$ & $R R=0.72(0.63$ to 0.82$)$ & $\begin{array}{l}\text { I: } 409 / 13406 \\
\text { C: } 301 / 6684\end{array}$ & $0.67(0.46,0.98)$ \\
\hline Pakistan ${ }^{51}$ ף & cNRCT & $\%$ diff=26\%; $p<0.001$ & $\begin{array}{l}\text { I: } 149 / 4665 \\
\text { C: } 47 / 1194\end{array}$ & $0.80(0.52,1.22)$ \\
\hline
\end{tabular}

Neonatal period reported is $0-27$ days. Infant period is $0-11$ months. Child mortality period is $0-59$ months. India ${ }^{46}$ also reports mortality separately for early ( $0-6$ days) neonates: $\%$ diff $=57.3 \% ; p<0.001$; calculated $R R=0.45$, and late $(7-27$ days) neonates: $\%$ diff $=51.6 \%$; calculated $R R=0.31$. Study also found a reduction in perinatal mortality $\%$ diff $=71.0 \% ; p<0.001$. A 2005 summary of this field trial reports that reductions in neonatal mortality and infant mortality reached 70\% (95\% Cls: 59, 81\%) and 57\% (95\% Cls: 46, 68\%), respectively, after 8 years postintervention. ${ }^{65}$ India ${ }^{47}$ also reports mortality for neonates after the first day of life: AHR=0.86 (0.79 to 0.95$)$; calculated $\mathrm{RR}=0.93$. Study also found a reduction in perinatal ( $\mathrm{AHR}=0.89 ; 95 \% \mathrm{Cls:} 0.78$ to 1.00 ) and postneonatal (AHR=0.76; $95 \% \mathrm{Cls:} 0.67$ to 0.85 ) mortality. Nepal ${ }^{50}$ reports no overall infant mortality, only by infant age brackets; denominators for calculated infant and childhood risks are based on study report that initial census registered ${ }^{66} 84$ children (control) and an additional 6722 were born during the study for a total of 13406 children available (intervention). Pakistan ${ }^{51}$ compares mortality rates between intervention and control periods for the 1985-1986 postintervention period; calculated risks are for 1985 only for which the study reports number of children per arm. Nepal ${ }^{50}$ and Pakistan $^{51}$ also report disease-specific mortality rates; results not shown. The South Africa ${ }^{39}$ study found no effect (RR=0.97; $95 \%$ Cls: 0.67 to 1.40$)$ on the primary joint mortality-morbidity outcome: HIV-free infant survival at 12 weeks among HIV-positive mothers.

*The study design reported is the nature of the comparative data, not necessarily the design as described by study authors.

†The before-after (BA) studies ${ }^{42} 430$ reported each annual time point compared with baseline; here we present end-line to baseline risk ratios.

†Reviewer (CW) calculated risk of death for intervention (I) and comparison (C) groups by taking number of events over number of live births (or, if unavailable, over population). For CBA, cRCT and cNRCT study designs, risks were calculated and compared (ie, calculated risk ratio) for the postintervention period between intervention and control groups; for BA study designs, intervention risk was calculated at end-line and control risk at baseline.

§Risk ratios and $95 \%$ Cls are adjusted for clustering.

ๆStudy primary outcome(s).

AHR, adjusted HR; BA, before-after; CBA, controlled before-after; cNRCT, cluster non-randomised controlled trial; cRCT, cluster randomised controlled trial; RR, risk ratio.

villages $(\mathrm{AOR}=0.03 ; 95 \%$ CIs: 0.02 to 0.07$)$, respectively. The Haryana ${ }^{48}$ study found significant reductions in danger signs (adjusted RR (ARR) $=0.82 ; 95 \%$ CIs: 0.67 to 0.99 ) and local infection (ARR $=0.91 ; 95 \%$ CIs: 0.71 to 1.17 ) among neonates, as well as diarrhoea $(\mathrm{ARR}=0.63 ; 95 \%$ CIs: 0.49 to 0.80$)$ and pneumonia
(ARR=0.60; 95\% CIs: 0.46 to 0.78$)$ among infants. The urban South Africa ${ }^{39}$ and Dominican Republic ${ }^{52}$ studies found no effects on childhood diarrhoea, a secondary intervention outcome.

The Dominican Republic ${ }^{52}$ study found that monthly home visits and mother's groups to promote healthy 

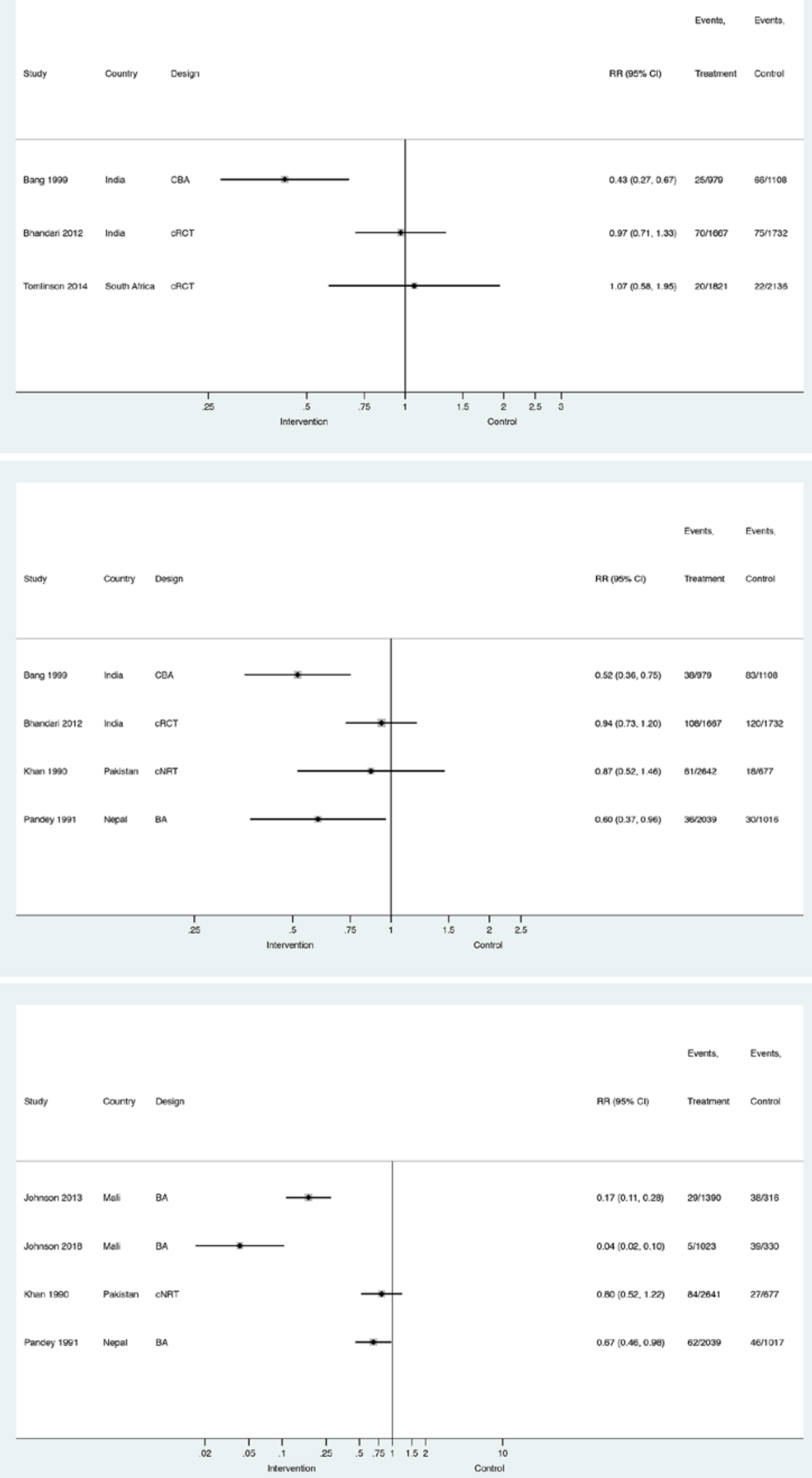

Figure 1 Forest plots for neonatal (top), infant (middle) and under 5 (bottom) mortality. CBA, controlled before-after; RR, risk ratio. 
Table 3 Intervention effects on morbidity and access to care outcomes

\begin{tabular}{|c|c|c|c|c|}
\hline Country & Design* $^{*}$ & Population/condition $†$ & $\begin{array}{l}\text { Reported measure of effect }(95 \% \\
\text { Cls)‡ }\end{array}$ & Calculated RR $(95 \%$ Cls)§ \\
\hline \multicolumn{5}{|c|}{ Prevalence of infectious diseases } \\
\hline $\mathrm{DR}^{52}$ & CNRCT & Diarrhoea, children under two & AOR=0.99 (0.59 to 1.67$)$ & 0.95 (0.61 to 1.47$)$ \\
\hline India ${ }^{48}$ & $\mathrm{cRCT}$ & Infant ${ }^{\star *}$ diarrhoea & $\mathrm{ARR}=0.63(0.49$ to 0.80$)$ & $0.63(0.54$ to 0.74$)$ \\
\hline India ${ }^{48}$ & $\mathrm{cRCT}$ & Infant*^ pneumonia & ARR $=0.60(0.46$ to 0.78$)$ & $0.56(0.40$ to 0.77$)$ \\
\hline Mali $^{42}$ & $\mathrm{BA}$ & Childhood febrile illness & $P R=0.61 ; p<0.001$ & $0.61(0.51$ to 0.73$)$ \\
\hline $\mathrm{Mali}^{43}$ & $\mathrm{BA}$ & Childhood febrile illness & $\mathrm{AOR}=0.45(0.32$ to 0.62$)$ & 0.57 (0.47 to 0.68$)$ \\
\hline Senegal ${ }^{45}+\dagger$ & CBA & Malaria, all ages & $\mathrm{AOR}=0.03(0.02$ to 0.07$)$ & $0.06(0.02$ to 0.18$)$ \\
\hline $\mathrm{SA}^{39}$ & $\mathrm{cRCT}$ & Infant diarrhoea at 12 weeks & $\mathrm{RR}=1.01(0.90$ to 1.14$)$ & $1.02(0.90$ to 1.16$)$ \\
\hline \multicolumn{5}{|c|}{ Prevalence of nutritional outcomesł¥ } \\
\hline $\mathrm{DR}^{52}+\dagger$ & cNRCT & Stunting, children under 2 & $\mathrm{AOR}=0.50(0.22$ to 1.10$)$ & 0.61 (0.33 to 1.11$)$ \\
\hline $\mathrm{DR}^{52}+\dagger$ & cNRCT & Overweight, children under 2 & $\mathrm{AOR}=0.43(0.23$ to 0.77$)$ & $0.69(0.47$ to 1.03$)$ \\
\hline $\mathrm{DR}^{52}+\dagger$ & cNRCT & LAZ scores, children under 2 & $\mathrm{MD}=0.21(-0.02$ to 0.44$)$ & NA \\
\hline $\mathrm{DR}^{52}+\dagger$ & cNRCT & BAZ scores, children under 2 & $\mathrm{MD}=-0.31(-0.49$ to -0.12$)$ & NA \\
\hline India ${ }^{48}$ & $\mathrm{cRCT}$ & Infant stunting & ARR $=0.99(0.94$ to 1.04$)$ & $1.03(0.93$ to 1.14$)$ \\
\hline India ${ }^{48}$ & cRCT & Infant wasting & $\mathrm{ARR}=1.10(0.90$ to 1.36$)$ & $1.16(0.93$ to 1.46$)$ \\
\hline $\mathrm{SA}^{39}$ & cRCT & Infant LAZ scores at 12 weeks & $\mathrm{MD}=0.11(0.03$ to 0.19$)$ & NA \\
\hline $\mathrm{SA}^{39}$ & $\mathrm{cRCT}$ & Infant WLZ scores at 12 weeks & $M D=0.01(-0.07$ to 0.09$)$ & NA \\
\hline $\mathrm{SA}^{39}$ & $\mathrm{cRCT}$ & Infant WAZ scores at 12 weeks & $\mathrm{MD}=0.09$ (0.00 to 0.18$)$ & NA \\
\hline \multicolumn{5}{|c|}{ Hospitalisation§§ } \\
\hline Bangladesh ${ }^{49}+\dagger$ & CNRCT & For diarrhoea, all ages & $\%$ diff=29\%; $p<0.01$ & 0.38 (0.34 to 0.41$)$ \\
\hline $\mathrm{DR}^{52}$ & cNRCT & During first 2 years of life & $\mathrm{AOR}=1.09$ (0.70 to 1.68$)$ & 1.07 (0.77 to 1.49$)$ \\
\hline India ${ }^{48}$ & $\mathrm{cRCT}$ & During infancy** & ARR $=0.67(0.51$ to 0.88$)$ & $0.65(0.46$ to 0.91$)$ \\
\hline $\mathrm{SA}^{39}$ & cRCT & For infant diarrhoea at 12 weeks & $\mathrm{RR}=1.28$ (0.75 to 2.19$)$ & 1.26 (0.67 to 2.39$)$ \\
\hline \multicolumn{5}{|c|}{ Access to effective $\| \eta$ treatment } \\
\hline $\mathrm{DR}^{52}$ & cNRCT & Diarrhoea, children under two & $\mathrm{AOR}=3.86(1.14$ to 13.02$)$ & 1.29 (0.79 to 2.12$)$ \\
\hline India ${ }^{48}+\dagger$ & $\mathrm{cRCT}$ & Infant ${ }^{\star \star}$ diarrhoea & ARR=1.22 (1.06 to 1.42$)$ & $1.25(1.11$ to 1.41$)$ \\
\hline India ${ }^{48}+\dagger$ & $\mathrm{cRCT}$ & Infant** pneumonia & $A R R=1.44(1.00$ to 2.08$)$ & $1.24(0.71$ to 2.14$)$ \\
\hline \multicolumn{5}{|c|}{ Access to prompt ${ }^{* * *}$ treatment } \\
\hline India ${ }^{48}+\dagger$ & cRCT & Infant ${ }^{\star \star}$ diarrhoea & ARR $=0.99(0.89$ to 1.10$)$ & $1.00(0.88$ to 1.14$)$ \\
\hline India ${ }^{48}+\dagger$ & $\mathrm{cRCT}$ & Infant*^ pneumonia & $\mathrm{ARR}=1.10(0.96$ to 1.25$)$ & 1.01 (0.84 to 1.22$)$ \\
\hline Mali $^{42}+\dagger$ & $\mathrm{BA}$ & Childhood malaria & $P R=1.89 ; p=0.0195$ & 1.89 (1.18 to 3.05$)$ \\
\hline Mali $^{43}+\dagger$ & $\mathrm{BA}$ & Childhood malaria & $\mathrm{AOR}=3.20(1.75$ to 5.85$)$ & 2.39 (1.49 to 3.83$)$ \\
\hline
\end{tabular}

${ }^{*}$ The study design reported is the nature of the comparative data in this review.

†Neonatal period is 0-27 days, infant period is $0-11$ months and childhood is under 5 years of age, unless otherwise indicated.

¥The BA studies ${ }^{42} 4350$ reported each annual time point compared with baseline; here we present effect estimates comparing end-line to baseline. $\S$ For CBA, CRCT and CNRCT study designs, risks were calculated and compared for the postintervention period between intervention and control groups; for BA designs, intervention risk was calculated at end-line and control risk at baseline. Risk ratios and $95 \%$ Cls are adjusted for clustering.

IFor the Dominican Republic, ${ }^{52}$ India, ${ }^{48} \mathrm{Mali}^{42}{ }^{43}$ and South Africa ${ }^{39}$ studies, prevalence based on mother's reporting of condition during 2 weeks period preceding the interview; for the Senegal ${ }^{45}$ study, prevalence measured at each time point by positive rapid diagnostic test of symptomatic community members.

${ }^{\star *}$ The India ${ }^{48}$ study also reported effects of similar magnitude at 6 months of age; results not shown. Study found a reduction in neonatal morbidity: danger signs (ARR=0.82; $95 \%$ Cls: 0.67 to 0.99) and infection (ARR=0.91; 95\% Cls: 0.71 to 1.17 ), and an increase in access to care for neonates: treatment by appropriate provider for danger signs (ARR=1.76; $95 \%$ Cls: 1.36 to 2.24 ), prompt treatment for danger signs (ARR=1.14; $95 \%$ Cls: 1.10 to 1.18 ), treatment by appropriate provider for infections ( $\mathrm{ARR}=4.86 ; 95 \% \mathrm{Cls}$ : 3.80 to 6.21 ) and prompt treatment for infections (ARR=1.97; 95\% Cls: 1.71 to 2.27 ).

††Study primary outcome(s).

损ased on anthropometric measures for all studies.

$\S \S$ Measure based on mother's recall for Dominican Republic ${ }^{52}$ (last 12 months), India ${ }^{48}$ (last 3 months) and South Africa ${ }^{39}$ (recall period not specified)

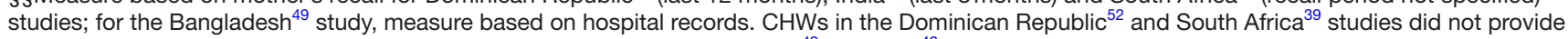
doorstep treatment but referred all cases detected; CHWs in the Bangladesh ${ }^{49}$ and India ${ }^{48}$ studies provided doorstep treatment and referral.

११Defined for the Dominican Republic ${ }^{52}$ study as oral rehydration for childhood diarrhoea, and for the India ${ }^{48}$ study as treatment from an appropriate provider, which included physicians in government and private facilities, auxiliary nurse midwife, Anganwadi worker (CHW) or ASHA. ${ }^{48}$

${ }^{\star * \star}$ Defined as treatment within 24 hours of symptom onset for all studies.

AOR, adjusted OR; ARR, adjusted risk ratio; ASHA, accredited social health activists; BA, before-after; BAZ, Body Mass Index-for-age; CBA, controlled before-after; CHW, community health worker; CNRCT, cluster non-randomised controlled trial; $\mathrm{CRCT}$, cluster randomised controlled trial; LAZ, length-forage; MD, mean difference; NA, not applicable; RR, risk ratio; WAZ, weight-for-age; WLZ, weight-for-length. 

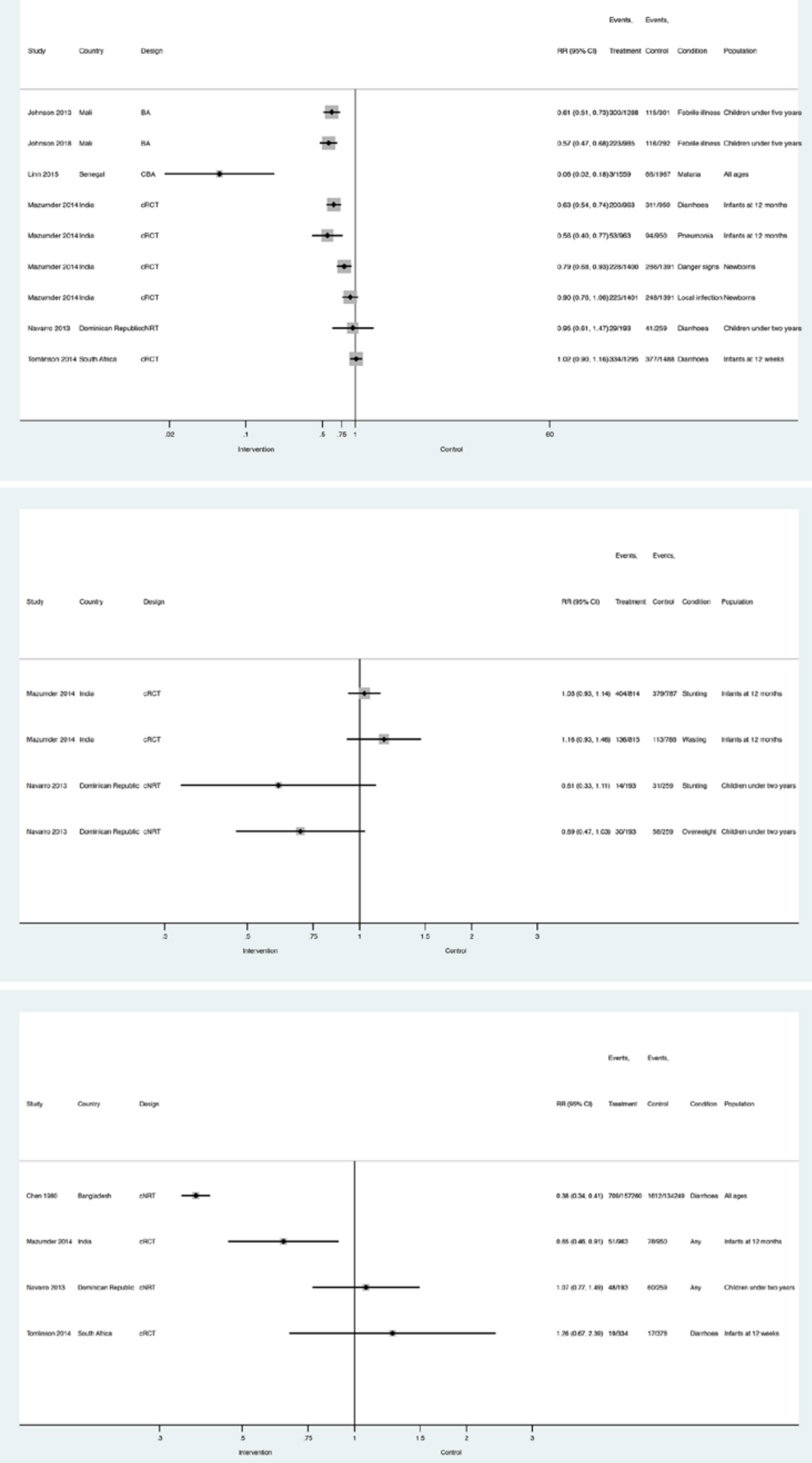

Figure 2 Forest plots for prevalence of common childhood infections (top) and nutritional conditions (middle), and hospitalisation (bottom). BA, before-after; CBA, controlled before-after; RR, risk ratio. 
babies and monitor physical growth during the first 2 years of life led to reductions in stunting ( $\mathrm{AOR}=0.50$; $95 \%$ CIs: 0.22 to 1.10$)$ and risk of overweight $(\mathrm{AOR}=0.43$; 95\% CIs: 0.23 to 0.77 ), compared with standard facilitybased controls. The Haryana ${ }^{48}$ study found no effect on wasting (ARR=0.99; 95\% CIs: 0.94 to 1.04 ) or stunting (ARR $=1.10 ; 95 \%$ CIs: 0.90 to 1.36$)$ at 12 months of age in exploratory analyses. The South Africa ${ }^{39}$ study found an increase in infant weight-for-age (mean difference $(\mathrm{MD})=0.09$; SD: $0.00,0.18)$ and length-for-age $(\mathrm{MD}=0.11$; SD: $0.03,0.19)$ z-scores, but not weight-for-length (MD=0.01; SD: -0.07, 0.09).

In Bangladesh, ${ }^{49} \mathrm{CHW}$ home visits to inquire about diarrhoea and offer oral rehydration therapy packets free of charge were associated with a $29 \%$ reduction $(p<0.01)$ in hospitalisation for diarrhoea compared with control villages with CHWs doing 'surveillance and health work'. In the Haryana ${ }^{48}$ study, in which CHWs assessed newborns for signs of illness at each visit and treated or referred them, caregivers in the intervention clusters reported fewer hospital admissions during infancy (ARR $=0.67 ; 95 \%$ CIs: 0.51 to 0.88$)$. In the South Africa $^{39}$ and Dominican Republic ${ }^{52}$ studies, where proactive CHWs did not offer doorstep treatment but referred all cases detected, caregivers reported more hospital admissions for their children, although results were not statistically significant.

\section{Access to treatment}

Four studies assessed access to effective and/or prompt treatment (table 3; Figure 3). Proactive case detection may increase access to effective treatment (calculated RRs range from 1.59 to $4.64 ; \mathrm{I}^{2}=97.0 \%$ ) (low certainty evidence). It is uncertain whether proactive case detection increases access to prompt treatment (calculated RRs range from 1.00 to $2.39 ; \mathrm{I}^{2}=84.9 \%$ ) because the certainty

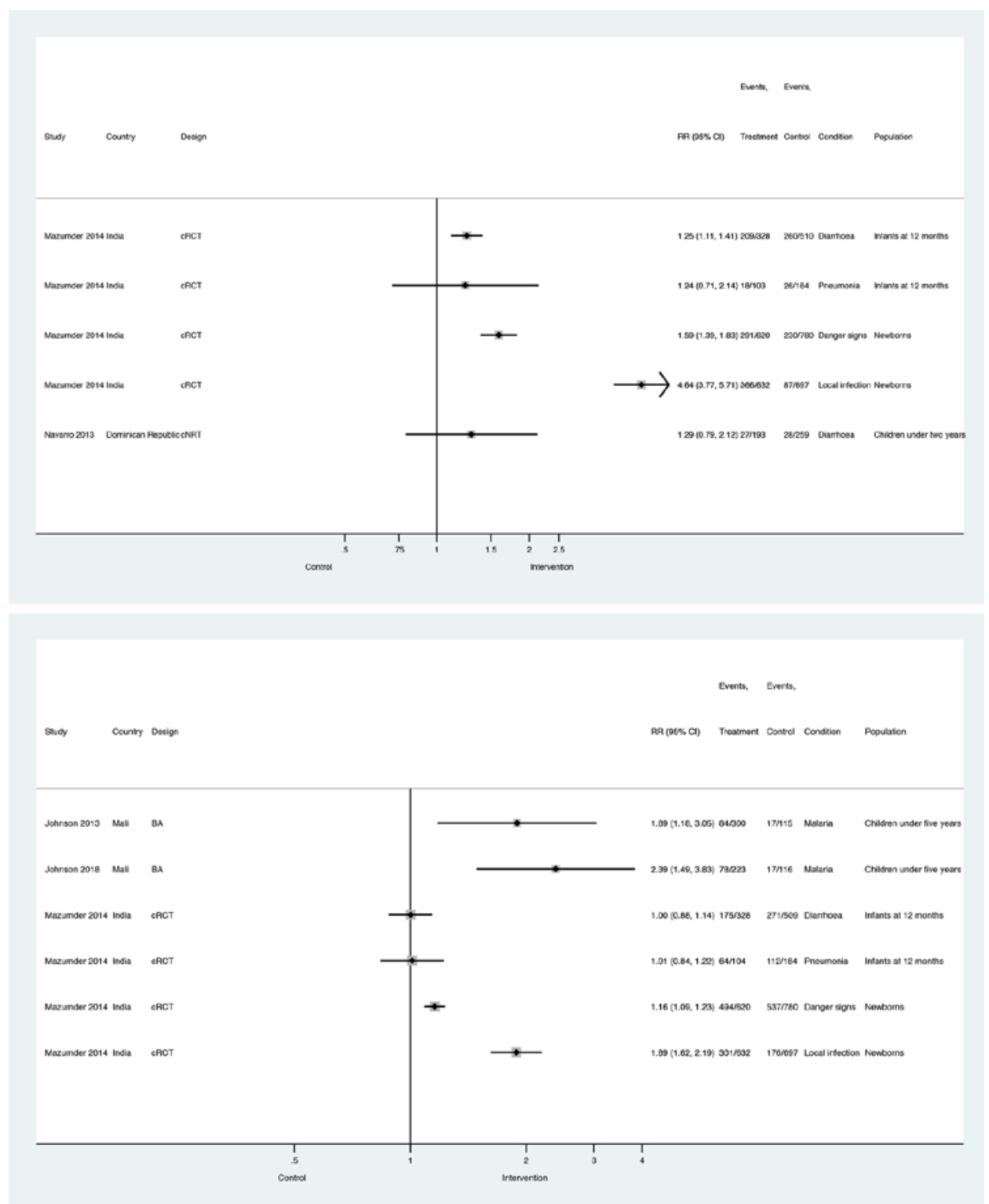

Figure 3 Forest plots for access to effective treatment (top) and prompt access to treatment (bottom). RR, risk ratio. 
of this evidence is very low. Three studies assessed the effects of proactive case detection of HIV and/or tuberculosis on access to diagnostic services and/or treatment adherence support; these were excluded from the main analysis and summarised in online supplementary file 4 .

In Dominican Republic, ${ }^{52}$ proactive home visits increased the proportion of diarrhoeal children who received oral rehydration solution $(\mathrm{AOR}=3.86 ; 95 \%$ CIs: 1.14 to 13.02$)$. In Haryana, ${ }^{48}$ caregivers in intervention clusters were more likely to seek any treatment within 24 hours and treatment from an appropriate provider for newborns with danger signs (respectively, $\mathrm{ARR}=1.14 ; 95 \%$ CIs: 1.10 to 1.18 and ARR=1.76; 95\% CIs: 1.36 to 2.24) and local infections (respectively, ARR $=1.97 ; 95 \%$ CIs: 1.71 to 2.27 and $A R R=4.86$; $95 \%$ CIs: 3.80 to 6.21 ). Caregivers were no more likely to seek any treatment within 24 hours for infants with diarrhoea ( $\mathrm{ARR}=0.99 ; 95 \%$ CIs: 0.89 to 1.10 ) or pneumonia ( $\mathrm{ARR}=1.10$; $95 \%$ CIs: 0.96 to $1.25)$, but more likely to seek treatment from an appropriate provider for diarrhoea (ARR $=1.22 ; 95 \%$ CIs: 1.06 to 1.42 ) or pneumonia ( $\mathrm{ARR}=1.44 ; 95 \%$ CIs: 1.00 to 2.08). In Mali, ${ }^{42}{ }^{43}$ a higher proportion of children with fever received antimalarial treatment within 24 hours of symptom onset compared with baseline (AOR $=3.20 ; 95 \%$ CIs: 1.75 to 5.85 ).

\section{DISCUSSION}

\section{Summary and quality of evidence}

This review identified 14 studies of 11 different interventions involving proactive case detection of common childhood conditions by CHWs in nine LMICs. Findings are summarized in table 4 . Proactive case detection may reduce infant mortality and increase access to effective treatment compared with conventional communitybased healthcare delivery (low certainty evidence). Although our review suggests that proactive case detection may also reduce mortality among children under 5 years, prevalence of infectious diseases, hospitalisation and improve access to prompt treatment, it is uncertain because the certainty of this evidence is very low. Proactive case detection may reduce neonatal mortality and improve nutritional outcomes (low certainty evidence), although effects vary and it is possible that it makes little or no difference to these outcomes.

Three high-quality studies from India $^{46-48}$ provide evidence that proactive case detection of illnesses among newborns and infants reduced neonatal and infant mortality, morbidity, and improve treatment seeking, compared with a conventional community-based approach. Two moderate quality studies in Senegal ${ }^{45}$ and Bangladesh $^{49}$ found that proactive case detection and doorstep treatment significantly reduced populationlevel morbidity, as measured by the prevalence of malarial fever and hospitalisation for diarrhoea, respectively. In these five studies, control groups received passive case detection and management from community-based CHWs and primary health facilities. This provides a more direct assessment of the effectiveness of proactive case detection than studies that had no CHWs in control clusters (which are likely to overestimate its effects) as well as studies with control CHWs who conduct home visits for other purposes (which are likely to underestimate its effects). Activities in control clusters may partially explain the null effects on neonatal mortality and infant morbidity found in the periurban South Africa cluster RCT. ${ }^{39}$ Home visits by control CHWs for the purpose of procuring identity documents and social grants may have served in practice to proactively identify sick children and encourage caregivers to seek care.

Our review extracted all study outcomes that met our inclusion criteria, even if those outcomes were the result of exploratory or posthoc analyses. This may account for some of the null effects in studies that reported numerous outcomes for which the study was not powered or for which the intervention had no clear pathway for impact. For example, finding no effect on prevalence of diarrhoea for visits targeting nutrition, ${ }^{52}$ and no effect on stunting for visits to detect disease in infants were the results of exploratory analyses and small sample sizes. ${ }^{47}$

Although this review found large inconsistencies in results for hospitalisation, the two studies in which CHWs provided doorstep treatment found a significant reduction, ${ }^{47} 49$ whereas the two urban studies ${ }^{39} 52$ in which all cases were referred found an increase (although statistically not significant), as might be expected. These were the only studies included in the main analyses in which CHWs did not offer doorstep treatment following proactive detection of uncomplicated cases. In the studies concerning HIV and/or tuberculosis, CHWs referred cases detected and then conducted follow-up home visits for treatment adherence support.

Most studies evaluated complex interventions with multiple components, limiting our ability to draw conclusions about the isolated effects of proactive case detection. At a minimum, all studies likely included-whether or not explicit in the intervention description-health promotion and education messaging by CHWs at the time of home visitation, the benefits of which on child health have been documented. ${ }^{55-57}$ Other cointerventions included additional support to proactive CHWs in the form of supervision and/or remuneration; systems strengthening such as facility-level improvements and/ or user fee removal; community mobilisation and/or women's groups. Studies that found the intervention effective, such as those in India, Senegal, Bangladesh and Mali, offered more in terms of supportive cointerventions, suggesting these are important design features of successful CHW programmes.

Overall, the quality of studies evaluating proactive case detection was poor. Our review identified only three cluster RCTs that evaluated mortality, morbidity or access to treatment; two of which were the same trial reporting different outcomes. ${ }^{478}$ Our results show clear design effect, with studies at higher risk of bias showing a larger magnitude of effect than the RCTs (tables 2 and 


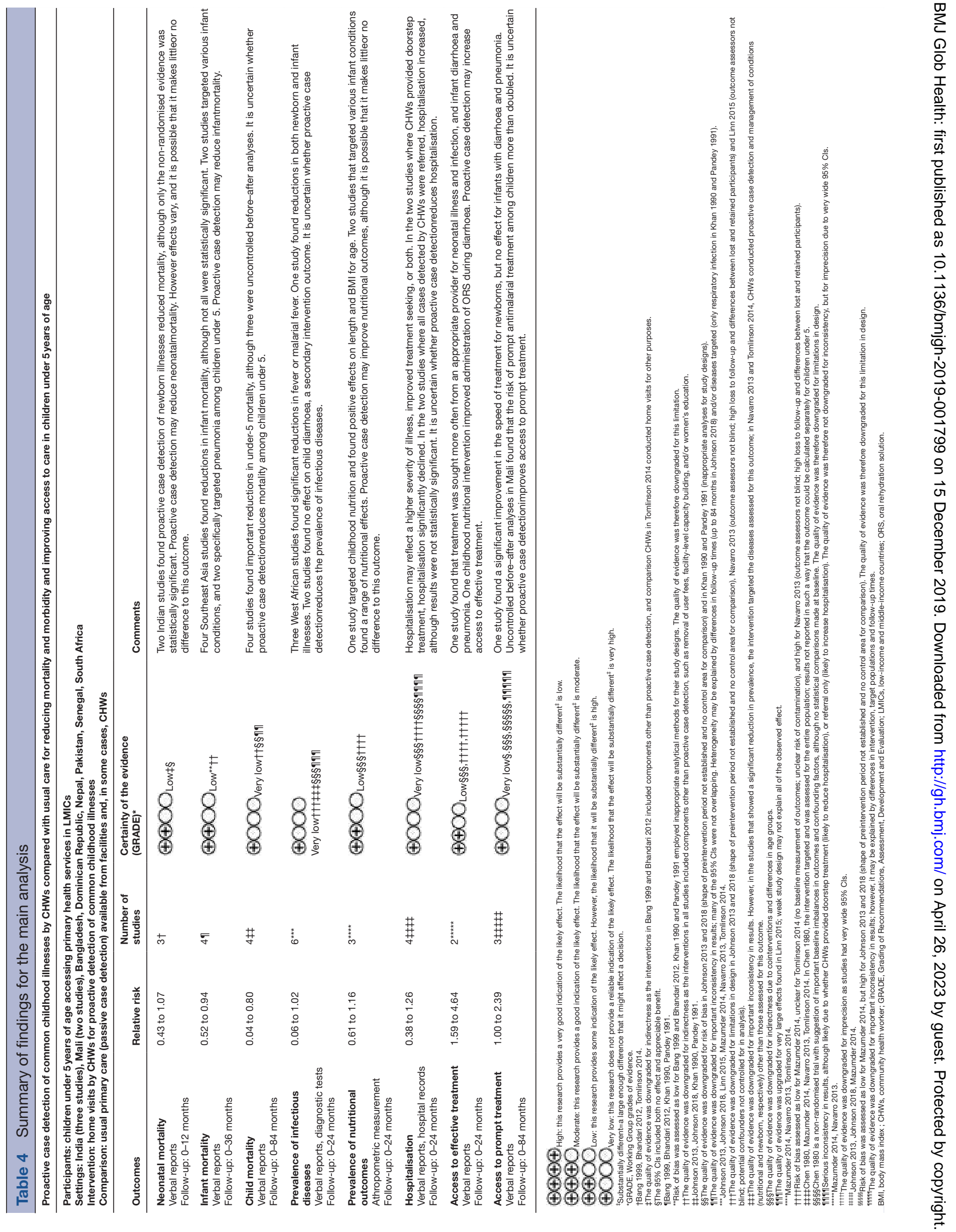


3; Figures 1 and 2). Risk of bias was higher still where inappropriate analytical methods were employed for the study design. ${ }^{50}{ }^{51}$ Additionally, studies published before the year 2000 did not account for clustering in their analytical approaches. ${ }^{46-51}$

\section{Limitations}

Our synthesis of evidence was limited by the small number of eligible studies, and the considerable diversity between them. With only 11 studies included in the main analyses, we were unable to conduct subgroup analyses that would have tested for differences in effectiveness by features in study and intervention design, including setting, CHW characteristics, target populations, diseases detected or frequency of home visits. We could not explore how different health conditions in different transmission settings or health system contexts would have differential impacts on outcomes. We were also unable to assess publication bias due to the limited number of studies. However, our review included large trials reporting statistically non-significant results, so there are no specific reasons for suspecting a high risk of publication bias.

Our synthesis was further limited by inadequate reporting of methods and results in some studies. We had to make some assumptions in order to calculate a principal summary measure for between study comparisons, such as approximating the denominator or postulating the ICC. Features of CHW intervention design and implementation, including CHW recruitment and training, support and supervision and health system integration, were inadequately described. Comparisons were also inadequately described, making it difficult to understand the differences between the two groups. In some cases, it was not clear whether the control included CHWs at all, ${ }^{44}$ what services were offered by control CHWs, including whether they conducted home visits for other purposes, ${ }^{40} 4149$ or whether they received the additional support, such as supervision or payment, offered to intervention CHWs. ${ }^{45}$

As there is no universally adopted terminology or strong indexation in health databases for the concept of proactive case detection, it is possible that some published or unpublished evaluations meeting the inclusion criteria were not identified through the search. There is a large body of evidence for the mortality, morbidity and access to care impacts of comprehensive community-based primary healthcare interventions, ${ }^{58} 59$ including household and community integrated management of childhood illness ${ }^{60-62}$ that may include home visits by community-based providers for the purpose of health promotion and education, vital registration and/ or proactive case detection. Some of these studies ${ }^{565763}$ may not have been included because insufficient information was available about the role of home visits in disease detection, study designs did not permit comparisons based on workflow and/or study designs were not sufficiently rigorous.

\section{Implications for research and practice}

The review process to inform the WHO guidelines for optimising CHW programmes found a scarcity of evidence for several areas reviewed, including recruitment and training, supervision and management, and health system integration. ${ }^{2964}$ Our review synthesising evidence around CHW workflow yielded similar conclusions regarding inadequate reporting of programme characteristics and lack of robust evidence. These features merit further consideration by programme architects and evaluators.

Standardising impact metrics for evaluating CHW programmes would greatly facilitate the synthesis of evidence in this field. Possible impact metrics include mortality among vulnerable groups, morbidity, as measured by disease prevalence, and access to prompt, effective treatment. Researchers should also consider process outcomes that provide an understanding of why and how a complex intervention did or did not work. None of the studies identified through the search provided a comparative costing analysis, or reported adverse effects of the intervention to patients, providers or the health system. These are important data points for practitioners and policymakers designing, implementing and scaling-up CHW interventions.

Finally, given that neonatal mortality is becoming an increasingly large proportion of mortality among children under 5 years of age, currently accounting for $45 \%$ of under-5 deaths, ${ }^{65}$ a systematic review dedicated to appraising the evidence of the effects of proactive case detection of neonatal conditions by CHWs in LMICs is merited.

\section{CONCLUSIONS}

Proactive case detection by CHWs may reduce child mortality and morbidity and increase access to care. The certainty of this evidence is low due to limitations in study designs, inconsistency in results, indirect measures of effect and important diversity between a small number of included studies. More research is needed on proactive case detection with rigorous study designs, standardised outcomes and measurement, and detail on intervention design and implementation.

\section{Author affiliations}

${ }^{1}$ Department of Disease Control, London School of Hygiene and Tropical Medicine, London, UK

${ }^{2}$ Division of Parasitic Diseases and Malaria, Centers for Disease Control and Prevention Center for Global Health, Atlanta, Georgia, USA

${ }^{3}$ Philadelphia College of Osteopathic Medicine, Georgia Campus, Suwanee, Georgia, USA

${ }^{4}$ Department of Medical Statistics, London School of Hygiene and Tropical Medicine, London, UK

${ }^{5}$ Malaria Research and Training Center, Université des Sciences des Techniques et des Technologies de Bamako, Bamako, Mali

${ }^{6}$ ZSFG Division of Hospital Medicine, University of California San Francisco, San Francisco, California, USA

Acknowledgements We are grateful to the London School of Hygiene and Tropical Medicine librarians for their tips on devising and executing the search strategy. 
Contributors $\mathrm{CW}$ designed the study and wrote the protocol with input from JT, $J G, B G, D C, K K$ and ADJ. CW developed and conducted the database searches. CW, JT and JG screened references for eligibility. CW and EW extracted data from included studies and conducted risk of bias assessments. CW analysed and synthesised data, with input from CL, KK, BG and DC. CW, JT and JG conducted GRADE quality assessments for all outcomes. CW drafted the manuscript. JT, JG, $\mathrm{CL}, \mathrm{BG}$ and $\mathrm{DC}$ provided critical intellectual feedback and assisted in revising the manuscript. All authors read and approved the final manuscript.

Funding The authors have not declared a specific grant for this research from any funding agency in the public, commercial or not-for-profit sectors.

Disclaimer The findings and conclusions presented in this report are those of the authors and do not necessarily reflect the official position of the CDC.

Competing interests CW, KK and ADJ are coauthors on one (CW and KK) or two (ADJ) of the studies included in the review.

Patient and public involvement statement No patient or members of the public were involved in this study.

Patient consent for publication Not required.

Provenance and peer review Not commissioned; externally peer reviewed.

Data availability statement No data are available.

Open access This is an open access article distributed in accordance with the Creative Commons Attribution Non Commercial (CC BY-NC 4.0) license, which permits others to distribute, remix, adapt, build upon this work non-commercially, and license their derivative works on different terms, provided the original work is properly cited, appropriate credit is given, any changes made indicated, and the use is non-commercial. See: http://creativecommons.org/licenses/by-nc/4.0/.

ORCID iD

Caroline Whidden http://orcid.org/0000-0003-0570-4632

\section{REFERENCES}

1 Rasanathan K, Muñiz M, Bakshi S, et al. Community case management of childhood illness in sub-Saharan Africa - findings from a cross-sectional survey on policy and implementation. J Glob Health 2014;4:020401.

2 Boschi-Pinto C, Labadie G, Dilip TR, et al. Global implementation survey of integrated management of childhood illness (IMCI): 20 years on. BMJ Open 2018;8:e019079-9.

3 Young M, Wolfheim C, Marsh DR, et al. World health Organization/ United nations children's fund joint statement on integrated community case management: an Equity-Focused strategy to improve access to essential treatment services for children. Am J Trop Med Hyg 2012;87:6-10.

4 Das JK, Lassi ZS, Salam RA, et al. Effect of community based interventions on childhood diarrhea and pneumonia: uptake of treatment modalities and impact on mortality. BMC Public Health 2013;13:S29.

5 Kidane G, Morrow $\mathrm{RH}$. Teaching mothers to provide home treatment of malaria in Tigray, Ethiopia: a randomised trial. The Lancet 2000;356:550-5

6 Munos MK, Walker CLF, Black RE. The effect of oral rehydration solution and recommended home fluids on diarrhoea mortality. Int $J$ Epidemiol 2010;39:i75-87.

7 Walker CLF, Black RE. Zinc for the treatment of diarrhoea: effect on diarrhoea morbidity, mortality and incidence of future episodes. Int $J$ Epidemiol 2010;39:i63-9.

8 Sazawal S, Black RE. Effect of pneumonia case management on mortality in neonates, infants, and preschool children: a metaanalysis of community-based trials. Lancet Infect Dis 2003;3:547-56.

9 Theodoratou E, Al-Jilaihawi S, Woodward F, et al. The effect of case management on childhood pneumonia mortality in developing countries. Int J Epidemiol 2010;39:i155-71.

10 Kalyango JN, Alfven T, Peterson S, et al. Integrated community case management of malaria and pneumonia increases prompt and appropriate treatment for pneumonia symptoms in children under five years in eastern Uganda. Malar J 2013;12:340.

11 Kalyango JN, Rutebemberwa E, Karamagi C, et al. High adherence to antimalarials and antibiotics under integrated community case management of illness in children less than five years in eastern Uganda. PLoS One 2013;8:e60481-8.

12 Mubiru D, Byabasheija R, Bwanika JB, et al. Evaluation of integrated community case management in eight districts of central Uganda. PLoS One 2015;10:e0134767-13.
13 Druetz T, Siekmans K, Goossens S, et al. The community case management of pneumonia in Africa: a review of the evidence. Health Policy Plan 2015;30:253-66.

14 Rutebemberwa E, Kadobera D, Katureebe S, et al. Use of community health workers for management of malaria and pneumonia in urban and rural areas in eastern Uganda. Am J Trop Med Hyg 2012;87:30-5

15 Druetz T, Ridde V, Kouanda S, et al. Utilization of community health workers for malaria treatment: results from a three-year panel study in the districts of Kaya and Zorgho, Burkina Faso. Malar J 2015;14:71.

16 Boone P, Elbourne D, Fazzio I, et al. Effects of community health interventions on under-5 mortality in rural Guinea-Bissau (EPICS) a cluster-randomised controlled trial. The Lancet Global Health 2016;4:e328-35.

17 Mukanga D, Tiono AB, Anyorigiya T, et al. Integrated community case management of fever in children under five using rapid diagnostic tests and respiratory rate counting: a multi-country cluster randomized trial. Am J Trop Med Hyg 2012;87:21-9.

18 Yansaneh Al, Moulton LH, George AS, et al. Influence of community health volunteers on care seeking and treatment coverage for common childhood illnesses in the context of free health care in rura Sierra Leone. Trop Med Int Health 2014;19:1466-76.

19 Amouzou A, Hazel E, Shaw B, et al. Effects of the integrated community case management of childhood illness strategy on child mortality in Ethiopia: a cluster randomized trial. Am J Trop Med Hyg 2016;94:596-604.

20 Amouzou A, Kanyuka M, Hazel E, et al. Independent evaluation of the integrated community case management of childhood illness strategy in Malawi using a national evaluation platform design. Am J Trop Med Hyg 2016;94:574-83.

21 Munos M, Guiella G, Roberton T, et al. The independent evaluation of the rapid scale-up program to reduce under-five mortality in Burkina Faso. Submitted for publication 2015;94:584-95.

22 Hazel E, Bryce J, Bathwater O. On bathwater, babies, and designing programs for impact: evaluations of the integrated community case management strategy in Burkina Faso, Ethiopia, and Malawi. Am J Trop Med Hyg 2016;94:568-70.

23 World Health Organization. Health systems financing: the path to universal coverage, 2010.

24 Jacobs B, Price N. The impact of the introduction of user fees at a district hospital in Cambodia. Health Policy Plan 2004;19:310-21.

25 Nabyonga J, Desmet M, Karamagi H, et al. Abolition of costsharing is pro-poor: evidence from Uganda. Health Policy Plan 2005;20:100-8.

26 Lehmann U, Sanders D. Community health workers: what do we know about them? the state of the evidence on programmes, activities, costs and impact on health outcomes of using community health workers. Evidence and Information for Policy WHO, 2007.

27 Ofosu-Amaah V. National experience in the use of community health workers: a review of current issues and problems. Geneva: World Health Organization, 1983.

28 Bhattacharyya K, LeBan K, Winch P, et al. Community health worker incentives and Disincentives: how they affect motivation, retention, and sustainability. Arlington, Virginia: Published by the Basic Support for Institutionalizing Child Survival Project (BASICS II) for the United States Agency for International Development, 2001.

29 Geneva. Who guideline on health policy and system support to optimize community health worker programmes, 2018.

30 Cochrane Effective Practice and Organisation of Care (EPOC). Epoc resources for review authors, 2017. Available: epoc.cochrane.org/ epoc-resources-review-authors

31 Who/Unicef. Who / UNICEF joint statement integrated community case management: an equity-focused strategy to improve access to essential treatment services for children. United Nations Children's Fund, 2012: 8.

32 Lewin S, Munabi-Babigumira S, Glenton C, et al. Lay health workers in primary and community health care for maternal and child health and the management of infectious diseases. Cochrane Database of Systematic Reviews 2010;94.

33 Veritas Health Innovation. Covidence systematic review software.

34 Cochrane Effective Practice and Organisation of Care (EPOC). Suggested risk of bias criteria for EPOC reviews, 2017.

35 McKensie J, Ryan R, Di Tianna G. Cochrane consumers and communication review group: cluster randomised controlled trials.

36 Higgins JPTet al. Measuring inconsistency in meta-analyses. BMJ 2003;327:557-60.

37 Guyatt GH. GRADE : an emerging consensus on rating quality of evidence and strength of recommendations, 2008: 336.

38 Cochrane Effective Practice and Organisation of Care (EPOC). Reporting the effects of an intervention in EPOC reviews, 2018. 
Available: epoc.cochrane.org/resources/epoc-resourcesreviewauthors [Accessed 9 Jul 2018].

39 Tomlinson M, Doherty T, ljumba P, et al. Goodstart: a cluster randomised effectiveness trial of an integrated, community-based package for maternal and newborn care, with prevention of motherto-child transmission of HIV in a South African township. Trop Med Int Health 2014;19:256-66.

40 Uwimana J, Zarowsky C, Hausler $\mathrm{H}$, et al. Training community care workers to provide comprehensive TB/HIV/PMTCT integrated care in KwaZulu-Natal: lessons learnt. Trop Med Int Health 2012;17:488-96.

41 Uwimana J, Zarowsky C, Hausler $\mathrm{H}$, et al. Community-Based intervention to enhance provision of integrated TB-HIV and PMTCT services in South Africa. Int J Tuberc Lung Dis 2013;17:48-55.

42 Johnson AD, Thomson DR, Atwood S, et al. Assessing early access to care and child survival during a health system strengthening intervention in Mali: a repeated cross sectional survey. PLoS One 2013;8:e81304.

43 Johnson $\mathrm{AD}$, Thiero $\mathrm{O}$, Whidden $\mathrm{C}$, et al. Proactive community case management and child survival in periurban Mali. BMJ Global Health 2018;3:e000634.

44 Yassin MA, Datiko DG, Tulloch O, et al. Innovative community-based approaches doubled tuberculosis case notification and improve treatment outcome in southern Ethiopia. PLoS One 2013;8:e63174.

45 Linn AM, Ndiaye Y, Hennessee I, et al. Reduction in symptomatic malaria prevalence through proactive community treatment in rural Senegal. Trop Med Int Health 2015;20:1438-46.

46 Bang AT, Bang RA, Baitule SB, et al. Effect of home-based neonatal care and management of sepsis on neonatal mortality: field trial in rural India. Lancet 1999;354:1955-61.

47 Bhandari N, Mazumder S, Taneja S, et al. Effect of implementation of integrated management of neonatal and childhood illness (IMNCI) programme on neonatal and infant mortality: cluster randomised controlled trial. BMJ 2012;344:e1634.

48 Mazumder S, Taneja S, Bahl R, et al. Effect of implementation of integrated management of neonatal and childhood illness programme on treatment seeking practices for morbidities in infants: cluster randomised trial. BMJ 2014;349:94988-15.

49 Chen LC, Merson MH, Sarder AM, et al. Village-Based distribution of oral rehydration therapy packets in Bangladesh *. Am J Trop Med Hyg 1980;29:285-90.

50 Pandey MR, Daulaire NMP, Starbuck ES, et al. Reduction in total under-five mortality in Western Nepal through community-based antimicrobial treatment of pneumonia. Lancet 1991;338:993-7.

51 Khan AJ, Khan JA, Akbar M, et al. Acute respiratory infections in children: a case management intervention in Abbottabad district, Pakistan. Bulletin of the World Health Organization 1990;68:577-85.

52 Navarro JI, Sigulem DM, Ferraro AA, et al. The double task of preventing malnutrition and overweight: a quasi-experimenta community-based trial. BMC Public Health 2013;13:212.
53 Uwimana J, Zarowsky C, Hausler $\mathrm{H}$, et al. Training community care workers to provide comprehensive TB/HIV/PMTCT integrated care in KwaZulu-Natal: lessons learnt. Tropical Medicine International Health 2012;17:488-96.

54 Uwimana J, Zarowsky C, Hausler $\mathrm{H}$, et al. Community-Based intervention to enhance provision of integrated TB-HIV and PMTCT services in South Africa. int $j$ tuberc lung dis 2013;17:48-55.

55 Davis TP, Wetzel C, Hernandez Avilan E, et al. Reducing child global undernutrition at scale in Sofala Province, Mozambique, using care group volunteers to communicate health messages to mothers. Global Health: Science and Practice 2013;1:35-51.

56 Mann V, Eble A, Frost C, et al. Retrospective comparative evaluation of the lasting impact of a community-based primary health care programme on under- 5 mortality in villages around Jamkhed, India. Bull World Health Organ 2010;88:727-36.

57 Edward A, Ernst P, Taylor C, et al. Examining the evidence of underfive mortality reduction in a community-based programme in Gaza, Mozambique. Trans R Soc Trop Med Hyg 2007;101:814-22.

58 Perry HB, Rassekh BM, Gupta S, et al. Comprehensive review of the evidence regarding the effectiveness of community-based primary health care in improving maternal, neonatal and child health: 1. rationale, methods and database description. J Glob Health;7.

59 Freeman PA, Schleiff M, Sacks E, et al. Comprehensive review of the evidence regarding the effectiveness of community-based primary health care in improving maternal, neonatal and child health: 4 . child health findings. J Glob Health 2017;7.

60 CORE Group. Community-Based integrated management of childhood illness policy guidance, 2009.

61 CORE. The Child Survival Collaborations and Resources Group. The Household and Community Integrated Management of Childhood IIIness (HH/C IMCl) Framework : A Facilitator's Guide for Conducting Country Meetings on $\mathrm{HH} / \mathrm{C} / \mathrm{MCl}, 2003$.

62 Winch PJ, Leban K, Casazza L, et al. An implementation framework for household and community integrated management of childhood illness. Health Policy Plan 2002;17:345-53.

63 Perry HB, Shanklin DS, Schroeder DG. Impact of a communitybased comprehensive primary healthcare programme on infant and child mortality in Bolivia: 14.

64 Scott K, Beckham SW, Gross M, et al. What do we know about community-based health worker programs? A systematic review of existing reviews on community health workers. Hum Resour Health 2018;16:1-17.

65 Black RE, Levin C, Walker N, et al. Reproductive, maternal, newborn, and child health: key messages from disease control priorities 3rd edition. Lancet 2016;388:2811-24.

66 Bang AT, Bang RA, Reddy HM. Home-Based neonatal care: summary and applications of the field trial in rural Gadchiroli, India (1993 to 2003). J Perinatol 2005;25:S108-22. 